\title{
POLYPHENOL VARIABILITY IN THE FRUITS AND JUICES OF A CIDER APPLE PROGENY
}

\author{
Cindy F. Verdu ${ }^{\mathrm{ab}, \mathrm{c}, \mathrm{d}}$, Nicolas, Childebrand ${ }^{\mathrm{b}, \mathrm{c}, \mathrm{d}}$, Nathalie Marnet $^{\mathrm{e}}$, Gildas Lebail ${ }^{\mathrm{e}}$, Fabrice \\ Dupuis $^{\mathrm{b}, \mathrm{c,d}}$, François Laurens ${ }^{\mathrm{b}, \mathrm{c}, \mathrm{d}}$, David Guilet ${ }^{\mathrm{a}}$, Sylvain Guyot ${ }^{\mathrm{e}, *}$
}

a'Université d'Angers, EA 921, Laboratoire de Substances d'Origine Naturelle et Analogues Structuraux, SFR 4207 QUASAV, PRES L'UNAM, 49045 Angers, France.

${ }^{\text {b}}$ Université d'Angers, UMR1345, Institut de Recherche en Horticulture et Semences, SFR 4207 QUASAV, PRES L'UNAM, 49045 Angers, France.

${ }^{\mathrm{c}}$ AgroCampus-Ouest, UMR1345, Institut de Recherche en Horticulture et Semences, 49045 Angers, France.

${ }^{\mathrm{d} I N R A, ~ U M R 1345, ~ I n s t i t u t ~ d e ~ R e c h e r c h e ~ e n ~ H o r t i c u l t u r e ~ e t ~ S e m e n c e s, ~} 49071$ Beaucouzé, France.

$J^{\mathrm{e}}$ INRA, UR1268 Biopolymères, Interactions \& Assemblages, Equipe «Polyphénols, Réactivité \& 'Procédés », 35650, Le Rheu, France.

*Corresponding author: Sylvain.Guyot@rennes.inra.fr; Tel.: +33 (0)2 234852 09; Fax: +33 (0)2 23 485210.

This article has been accepted for publication and undergone full peer review but has not been through the copyediting, typesetting, pagination and proofreading process, which may lead to differences between this version and the Version of Record. Please cite this article as doi: $10.1002 /$ jsfa.6411 


\begin{abstract}
BACKGROUND: Polyphenols have a favorable antioxidant potential on human health, suggesting that their high content in apple is responsible for the beneficial effects of apple consumption. They are also linked to the quality of apple juices and ciders since they are predominantly responsible for astringency, bitterness, color and aroma. Major phenolic compounds were quantified by liquid chromatography in fruits and juices from a cider apple progeny harvested for three years. The total content of procyanidins and their average degree of polymerization (DPn) were also determined in fruits by phloroglucinolysis. Variability and extraction yield of these compounds were determined.
\end{abstract}

RESULTS: The variability observed in the progeny was representative of the variability observed in many cider apple varieties. Hydroxycinnamic acids were the most extractable group, with an average extraction yield of $67 \%$, whereas flavonols and anthocyanins were the least.

CONCLUSION: This study is the first one to introduce variability and extraction yields of the main phenolic compounds in both fruits and juices of a cider apple progeny. This dataset will be used for an upcoming QTL mapping study, an original approach that has never been undertaken for cider apple.

KEYWORDS: Malus x domestica; cider apple; phenolic compound; extractability; phloroglucinolysis. 


\section{INTRODUCTION}

Apple is one of the most highly produced fruits in the world, with more than 69.5 million tons produced in 2010 over an area of 4.7 million hectares (FAO, http://faostat3.fao.org/). Cider is made using specific varieties of apple that are different from the ones used for dessert apple production. A large number of cider apple varieties are grown throughout the world, with a wide diversity in terms of organoleptic criteria (including astringency, bitterness, aroma, color and acidity), crop management and disease resistance. ${ }^{1}$ This variability among varieties in different countries is very pronounced, particularly with regard to their polyphenol composition..$^{2-4}$ For these reasons, they can serve as a relevant genetic resource for breeders. Six main phenolic groups are present in apple: flavanols, which are subdivided into monomers (i.e., catechins) and oligomers (i.e., procyanidins, also referred to as condensed tannins), hydroxycinnamic acids, dihydrochalcones, flavonols and anthocyanins. Hydroxycinnamic acids are mainly represented by 5 -caffeoylquinic acid (often referred to as chlorogenic acid), 4-caffeoylquinic acid and 4-p-coumaroylquinic acid. Flavanol monomers are mainly represented by $(+)$-catechin and (-)-epicatechin, the latter being the most abundant in apple. Procyanidins are the group with the highest global concentration in apple and the largest number of compounds. ${ }^{5}$ Each compound is differentiated by the nature of the constitutive flavanol units, the polymerization degree and the position of the interflavanic linkages. Therefore, this polydispersity (or the heterogeneity of the distribution of molecular masses) in apple makes it difficult to individually quantify procyanidin molecules with polymerization degrees above 3-4. However, the use of acidolysis in the presence of nucleophiles (i.e., thiolysis or phloroglucinolysis), coupled with HPLC analysis, makes it possible to characterize and quantify the global procyanidin fraction in crude apple samples. ${ }^{6}$

Dihydrochalcones are mainly represented by phloridzin (phloretin 2'-O-glucoside) and 
phloretin xyloglucoside in apple. Flavonols are essentially represented by quercetin glycosides, mainly avicularin (quercetin-3-O-arabinoside), hyperin (quercetin-3-Ogalactoside), isoquercitrine (quercetin-3-O-glucoside), quercitrin (quercetin-3-O-rhamnoside), reynoutrin (quercetin-3-O-xyloside) and rutin (quercetin-3-O-rutinoside). They are mainly present in the skin of the fruit, along with anthocyanins, essentially represented by ideain (cyanidin-3-O-galactoside). ${ }^{4}$

Phenolic compounds are directly linked to the major organoleptic criteria of apples and their products (apple juice, cider, etc.). Procyanidins are directly responsible for the astringent sensation resulting from their complexation with salivary proteins. They are also involved in the bitter taste of cider as the result of specific interactions with bitterness receptors in the mouth. The intensity of these sensory properties is directly linked to the procyanidin structures and, in particular, their degree of polymerization. ${ }^{7}$ Chlorogenic acid is the preferential substrate of the polyphenol oxidase. In the presence of oxygen, it is enzymatically converted into O-quinone, which further reacts with catechins, procyanidins and dihydrochalcones, resulting in the formation of oxidation products including yellow-orange molecules responsible for the color of apple juice and cider. ${ }^{8-10}$ Moreover, during the fermentation step of cider making, the ester hydrolysis of hydroxycinnamic acids could be the precursor of some aromatic compounds. ${ }^{11}$

In addition, it has been reported that phenolic compounds are involved in the health benefits of fruit and vegetable-rich diets. ${ }^{12}$ Apples are widely consumed throughout the world and are rich in strong antioxidant polyphenols, including quercetin, $(+)$-catechin, phloridzin and 5caffeoylquinic acid. Epidemiologic studies have shown that apple consumption is linked to the reduced risk of some cancers, cardiovascular disease, diabetes and asthma. ${ }^{13,14}$

A wide variability of phenolic compound concentrations is observed among apple varieties, and cider apple are usually more concentrated in polyphenols than dessert apple varieties., ${ }^{2,15}$ 
A considerable difference between the phenolic content of fruits and juices has already been reported. The work of Guyot et al. $^{6}$ on hydroxycinnamic acids, flavanols and dihydrochalcones has shown that the transferability of phenolic compounds during juice processing can be very different according to the variety. For example, it ranges from $57 \%$ for the 'Avrolles' variety, to $77 \%$ for the 'Kermerrien' variety. ${ }^{6}$ However, the juice of polyphenol-rich varieties has a higher phenolic compound content. This observation is also true for all phenolic groups. Differences among fruits and juices were mainly explained by the extraction yield of phenolic compounds during juice processing. Monomers and polymers of flavanols had the smallest transferability rate as a result of their high retention in the mash, explained by their affinity for cell wall components. ${ }^{16}$ The centrifugation of the juice further reduces the concentration of procyanidins and the mean polymerization degree by removing tannins associated with fruit solid parts suspended in the raw juice. ${ }^{6}$ Moreover, the release of polyphenoloxidase (PPO) during grinding in addition to juice oxygenation causes the degradation of some phenolic compounds. ${ }^{8}$ The addition of sodium fluoride during juice processing makes it possible to inactivate the PPO and to limit the degradation of compounds by oxidation. ${ }^{17}$

Numerous studies have focused on the genetic bases of phenolic compounds. ${ }^{18-21}$ Anthocyanins have been particularly well studied in fruits since they are major contributors to fruit quality. ${ }^{22-24}$ A cluster of three MYB genes involved in the anthocyanin content was identified following a QTL study on grape. ${ }^{22}$ In apple, two studies have recently been published on QTL detection of phenolic compounds measured in dessert apple progenies. ${ }^{25,26}$ Chagne et al. ${ }^{25}$ reported the quantification of 16 and 23 phenolic compounds in two different harvesting years using an ultra-high performance liquid chromatograph (UHPLC) coupled to a UV-PDA detector. Khan et al. $^{26}$ reported the quantification of 81 phenolic compounds belonging to the two groups of phenylpropanoids and polyphenols in the skin and the flesh, 
using a high performance liquid chromatograph (HPLC) coupled to a mass spectrometer associated with MSClust software. To our knowledge, these are the only studies that have been done on the variability of phenolic content existing within an apple progeny.

Since cider apples contain many more phenolic compounds than dessert apples, a progeny derived from a cross between a cider and a dessert apple was studied to perform a genetic study on phenolic content. An initial study was first carried out to develop a liquid chromatography method suitable for the quantification of major phenolic compounds in juices (Verdu et al., submitted).

\section{MATERIAL AND METHODS}

\section{Phenolic standards and chemicals}

LC/MS-grade MeOH was purchased from Carlo Erba reagents (Val de Reuil, France). Formic acid and acetic acid of LC/MS grade were obtained from Fisher Scientific (Illkirch, France). Ultrapure water was obtained from a MilliQ water purification system (Millipore S.A., Molsheim, France). Standards of procyanidins B1 and B2, 4-p-coumaroylquinic acid, 4caffeoylquinic acid and phloretin xyloglucoside were obtained from Polyphenol Biotech (Bordeaux, France). (+)-catechin, (-)-epicatechin, 5-caffeoylquinic acid, phloridzin and rutin were purchased from Sigma-Aldrich (Lyon, France). Hyperin, isoquercitrine and quercitrin were obtained from Extrasynthese (Genay, France), and avicularin was obtained from LGC Standards SARL (Molsheim, France). (-)-Epicatechin-phloroglucinol adduct was purified in the laboratory. Reynoutrin was identified according to its $\mathrm{m} / \mathrm{z}$ ratio and its retention time. ${ }^{27}$

\section{Plant material}

The material was a cider apple progeny consisting of 385 individuals derived from a cross between the hybrids X5210 and X8402. The former (X5210) is derived from the cider variety, 
'Kermerrien', whereas the latter (X8402) is a dessert apple hybrid whose grandparents include the two varieties, 'Florina' and 'Prima'.

The cross between X5210 and X8402 was made in 2000. Plantlets were selected in a greenhouse for scab and powdery mildew resistance. Trees were planted in 2003 at the INRA Horticulture Experimental Unit in Angers, France, with their roots.

This study was carried out both on fruit extracts and apple juices. Fruit extracts were prepared from 92 apples harvested in 2008 and 137 harvested in 2009 (referred to as F08 and F09, respectively, in this paper). Apple juices were prepared from 209 and 123 hybrids from the progeny harvested in 2009 and 2010, respectively (J09 and J10, respectively). The fruits were collected at the mature stage "when $50 \%$ of the fruits have fallen off the tree", which is the harvest stage used in commercial cider orchards.

\section{Sample preparation}

Fruit sampling and sample preparation

For each individual, 30 fruits were randomly collected from one tree and divided into three batches of ten fruits. For each batch, fruits were mechanically cut according to a systematic procedure that made it possible to randomly select four small pieces per fruit that were immediately frozen in liquid nitrogen. ${ }^{28}$ Samples were then freeze-dried and reduced to a fine and homogeneous powder with an electrical crusher (Retsch, model YGG, Bioblock Scientific). The powders were then kept under vacuum in a desiccator until analysis.

\section{Apple juice preparation}

The apple juice preparation consisted of mixing $330 \mathrm{~g}$ of cored apples using a juice extractor (Philips HR1865), adding sodium fluoride (200 $\mathrm{mg} \mathrm{L}^{-1}$ of apple juice) to limit oxidation of phenolic compounds, and centrifuging at $15000 \mathrm{~g}$ during $15 \mathrm{~min}$ (Sigma 4K15) to recover the 
clear apple juice. Following this preparation, one volume of methanol was added and the mixture was filtered on PTFE filters $(0.2 \mu \mathrm{m}$, Uptidisc, Interchim, France $)$ before chromatographic analysis.

\section{Quantification of phenolic compounds}

Analysis method for fruit extracts

Methanol extraction of freeze-dried powders

Simple polyphenols, including monomeric catechins, low molecular weight procyanidins, hydroxycinnamic acids, flavonols, dihydrochalcones and anthocyanins, were extracted from the powders using acidified methanol. Precisely weighted aliquots of powders (in the 50-100 mg range) were extracted using $1.2 \mathrm{ml}$ of pure methanol containing $1 \% \mathrm{v} / \mathrm{v}$ acetic acid for 15 min in an ultrasonic bath (Brasson 2200, USA). The mixture was then filtered on PTFE filters (0.45 $\mu \mathrm{m}$, Uptidisc, Interchim, France).

Acidolysis of procyanidin oligomers and polymers in the presence of phloroglucinol (phloroglucinolysis)

In previously published studies, ${ }^{5,6,29}$ acidolysis of procyanidins was applied on apple powders using an excess of benzylmercaptan as a nucleophilic agent (thiolysis reaction). Phloroglucinol rather than benzylmercaptan was used in this study because of its advantages (odorless and non-toxic). ${ }^{30,} 31$ Moreover, comparative assays using thiolysis or phloroglucinolysis revealed no significant differences in their efficiency to quantify and characterize the procyanidin fraction in crude apple samples. ${ }^{32}$ Interestingly, the phloroglucinolysis reaction leads to the depolymerization of procyanidin structures making the distinction between terminal and extension units of procyanidins. Then, quantitative HPLC analysis of the phloroglucinolysis media allows the determination of the total 
procyanidin concentration, the nature and the proportion of the constitutive units of procyanidins in the crude samples. This makes it possible to calculate their average degree of polymerization (DPn). ${ }^{29}$.

The phloroglucinolysis method was adapted from Kennedy and Jones. ${ }^{30}$ Freeze-dried apple powders $(30 \mathrm{mg})$ were treated with a solution of $0.3 \mathrm{M} \mathrm{HCl}$ in $\mathrm{MeOH}$ containing $75 \mathrm{~g} \mathrm{~L}^{-1}$ phloroglucinol and $10 \mathrm{~g} \mathrm{~L}^{-1}$ ascorbic acid at $50^{\circ} \mathrm{C}$ for $50 \mathrm{~min}$, and then combined with $1.2 \mathrm{~mL}$ of aqueous sodium acetate to stop the reaction. The mixture was then filtered on PTFE filters (0.45 $\mu \mathrm{m}$, Uptidisc, Interchim, France).

RP-HPLC of methanol extracts and phloroglucinolysis reaction media HPLC analysis was performed using a Waters 2690 separation module equipped with an autosampler, a cooling system set to $4^{\circ} \mathrm{C}$, and a Waters 996 photodiode array detector. The column was a $250 \mathrm{~mm} \times 4 \mathrm{~mm}$ ID with a bead diameter of $5 \mu \mathrm{m}$, and an end-capped Purospher RP 18 column (Merck) maintained at $30^{\circ} \mathrm{C}$. The mobile phase contained (A) $2.5 \%$ acetic acid and (B) acetonitrile, which was previously degassed and then continuously sparged with highpurity helium during analysis. The solvent system was a gradient of aqueous acetic acid, 2.5\% $\mathrm{v} / \mathrm{v}$ (solvent A), and acetonitrile (solvent B). The following gradient was applied at a constant flow rate of $1 \mathrm{ml} \cdot \mathrm{min}^{-1}$ : initial, 3\% B; 0-5 min, 9\% B linear; 5-15 min, 16\% B linear; 15-45 min, 50\% B linear, followed by washing and reconditioning of the column. The volume of injection was $10 \mu \mathrm{L}$.

The acquisition, integration and processing of the signal was controlled using Millennium software 2010, version 2.1. Simultaneous monitoring was performed at $280 \mathrm{~nm}$ for flavan-3ols and dihydrochalcones, $320 \mathrm{~nm}$ for hydroxycinnamic acids, $350 \mathrm{~nm}$ for flavonols, and 520 $\mathrm{nm}$ for anthocyanins. Spectra were recorded between 200 and $600 \mathrm{~nm}$. Phenolic compounds were identified on the basis of their retention times and their characteristic spectra in 
comparison to available standards. Except for the series of flavonols that were all quantified at $350 \mathrm{~nm}$ as hyperoside equivalent, the other phenolic compounds and phloroglucinolysis products were quantified using their own calibration curve: 5-caffeoylquinic acid and 4-pcoumaroylquinic acid were quantified at $320 \mathrm{~nm}$; (-)-epicatechin, $(+)$-catechin, procyanidins B1 and B2, phloretin xyloglucoside, phloridzin and epicatechin-PLG adduct were quantified at $280 \mathrm{~nm}$; and ideain, the only molecule from the anthocyanin class considered in this study, was quantified at $520 \mathrm{~nm}$ according to its own calibration curve.

\section{Analytic method for apple juices}

UHPLC analyses were performed using a Thermo Accela High Speed LC system (Thermo Scientific, Gometz le Châtel, France) equipped with a refrigerated autosampler. Samples were injected into a Zorbax Eclips Plus C18 column (50mmx2.1mm, $1.8 \mu \mathrm{m}$; Agilent) using a 10$\mu \mathrm{L}$ loop in partial loop mode. The column was heated at $30^{\circ} \mathrm{C}$ and was equipped with an inline filter $(0.2 \mu \mathrm{m})$ (Thermo Scientific). The solvent system was a gradient of aqueous formic acid, $0.1 \% \mathrm{v} / \mathrm{v}$ (solvent A), and methanol (solvent B). The following gradient was applied at a constant flow rate of $250 \mu \mathrm{L} \cdot \mathrm{min}^{-1}$ : initial, $0 \% \mathrm{~B}$; 0-1 min, $10 \% \mathrm{~B}$ linear; $1-3 \mathrm{~min}, 18 \% \mathrm{~B}$ linear; 3-11 min, 18.5\% B linear; 11-13 min, $21.5 \%$ B linear; 13-17 min, 25.5\% B linear; 17$21 \mathrm{~min}, 29 \%$ B linear; 21-23 $\mathrm{min}, 32 \% \mathrm{~B}$ linear; 23-35 $\mathrm{min}, 50 \%$ B linear, followed by washing and reconditioning of the column. The volume of injection was $1 \mu \mathrm{L}$. The MS experiments were performed with a Thermo TSQ Quantum Access MAX equipped with an electrospray interface (ESI) operating in the negative ionization mode. Each standard was infused into the electrospray ion source at $5 \mu \mathrm{g} \mathrm{mL}^{-1}$ in $\mathrm{MeOH}$ using a syringe pump at a flow rate of $250 \mu \mathrm{L} \min ^{-1}$ to determine the collision energy, the tube lens offset and the SRM transitions chosen to be the most sensitive with the lowest collision energy for each compound. The Selective Reaction Monitoring (SRM) mode was used to quantify phenolic 
compounds. The ESI conditions were as follow: spray voltage, $3500 \mathrm{~V}$; vaporizer temperature, $350^{\circ} \mathrm{C}$; sheath gas pressure, 48 arbitrary units (au); ion sweep gas, 1 au; auxiliary gas pressure, $13 \mathrm{au}$; capillary temperature, $200^{\circ} \mathrm{C}$; skimmer offset, 0 au. The collision gas used was argon at a pressure of 1.5 mTorr. The data were processed using Xcalibur software (2.1).

Phenolic compounds were identified on the basis of their retention times and their characteristic fragmentation pattern in comparison with available standards. Quantifications were performed in SRM mode, using the calibration curves of standards.

In addition to procyanidins $\mathrm{B} 1$ and $\mathrm{B} 2$, ten other major procyanidins were individually quantified by UHPLC-UV at $280 \mathrm{~nm}$ with a Thermo Accela PDA detector in juices prepared in 2010 to estimate the total content of flavanols.

\section{Statistical analyses}

Statistical analyses were performed with $\mathrm{R}$ software version 2.13.1. ${ }^{33}$ and GraphPadPrism 5.01 (GraphPad Software, San Diego, CA, USA).

Two separate analyses of variance (ANOVA) were performed for fruits and juices, to evaluate the genetic effect, the harvest year effect and the interaction genetic x year.

Principal component analyses (PCA) were performed for fruits and juices to estimate the correlation between different traits. Each year was analyzed separately because there were not enough individuals in common between the two harvest years.

Using the method of Guyot et al., ${ }^{6}$ the extraction yields were calculated for each compound, and each individual was analyzed for both fruit and juice phenolic content in 2009 as follows: Yield $(\%)=\left(\left(\left[\mathrm{C}_{\mathrm{j}}\right]^{*} \mathrm{R}\right) /\left[\mathrm{C}_{\mathrm{f}}\right]^{*} \mathrm{~d}\right) * 100$ where $\left[\mathrm{C}_{\mathrm{j}}\right]$ and $\left[\mathrm{C}_{\mathrm{f}}\right]$ were the concentration of the considered polyphenol in the juice $\left(\mathrm{mg} \mathrm{L}^{-1}\right)$ and in the fruit $\left(\mathrm{mg} \mathrm{kg}^{-1}\right)$, respectively. $\mathrm{R}$ was the 
extraction yield of the juice ( $\mathrm{kg}$ of juice per $\mathrm{kg}$ of fresh fruits) and $\mathrm{d}$ was the density of the juice $\left(\mathrm{kg} \mathrm{L}^{-1}\right)$.

\section{RESULTS AND DISCUSSION}

\section{Phenolic compounds in fruits}

Four flavanols ((+)-catechin, (-)-epicatechin, procyanidins B1 and B2), six flavonols (avicularin, hyperoside, isoquercitrin, quercitrin, reynoutrin and rutin), two hydroxycinnamic acids (5-caffeoylquinic acid and 4-p-coumaroylquinic acid), two dihydrochalcones (phloridzin and phloretin xyloglucoside) and the anthocyanin ideain, were measured by HPLC-UV for two harvest years. The phloroglucinolyse reaction was used to estimate the total content of procyanidins and the average degree of polymerization of flavanols.

The total concentration of polyphenols in fruit samples was comprised between 1058 and $6418 \mathrm{mg} \mathrm{kg}^{-1}$ of fresh weight (FW), with an average concentration of $2707 \mathrm{mg} \mathrm{kg}^{-1}$ (Table 1). These results are in agreement with total polyphenol concentrations determined in different cider and dessert apple varieties (Table 2). The lowest concentration obtained in our progeny was close to the ones determined for the 'Golden Delicious' (a dessert apple variety) and 'Judor' varieties (1040 $\mathrm{mg} \mathrm{kg}^{-1}$ of $\left.\mathrm{FW}\right)$, and the highest was close to that of the cider variety 'Jeanne Renard' (6990 mg kg-1 of FW). ${ }^{2}$ This wider range observed in our progeny could be explained by the parents: X5210, a descendant of the cider apple variety, 'Kermerrien' (4500 $\mathrm{mg} \mathrm{kg}{ }^{-1}$ of FW in Sanoner et $\mathrm{al}^{2}$ ), and X8402 (1400 $\mathrm{mg} \mathrm{kg}^{-1}$ of FW in our experiment), a descendant of the dessert apple variety, 'Florina' (2240 $\mathrm{mg} \mathrm{kg}^{-1}$ of FW in Wojdylo et al. ${ }^{34}$ ).

Phloroglucinolysis coupled to HPLC analysis revealed that the most concentrated group was the flavanols, which represented $65 \%$ of average total polyphenols in the fruit (Table 1). The total content of flavanols ranged from 592 to $4769 \mathrm{mg} \mathrm{kg}^{-1}$ of $\mathrm{FW}$, with an average 
concentration of $1761 \mathrm{mg} \mathrm{kg}^{-1}$. These results were consistent with other results obtained on cider varieties, with a total flavanol content ranging from 621 to $6195 \mathrm{mg} \mathrm{kg}^{-1}$ of FW. ${ }^{2}$ The most concentrated compounds within flavanols were (-)-epicatechin and procyanidin B2, with both concentrations close to $210 \mathrm{mg} \mathrm{kg}^{-1} \mathrm{FW}$ (Fig. 1). They ranged from 33 to $574 \mathrm{mg} \mathrm{kg}^{-1}$ of FW for (-)-epicatechin, and from 49 to $460 \mathrm{mg} \mathrm{kg}^{-1}$ of FW for procyanidin B2 (without one outlier at $730 \mathrm{mg} \mathrm{kg}^{-1}$ ). These concentrations were consistent with previous studies (Table 2). The polymerization degree (DPn) of the flavanol class in the progeny was 3.0, ranging from 2.1 to 5.6. This result was consistent with major cider varieties, mainly comprised between 3.7 and 7.5. However, some varieties such as 'Guillevic' and 'Avrolles' could have a DPn that was higher than $40 .{ }^{2,3}$

The second most concentrated group was hydroxycinnamic acids, with $26.4 \%$ of average total polyphenols (Table 1). The concentration of hydroxycinnamic acids in the progeny ranged from 86 to $2000 \mathrm{mg} \mathrm{kg}^{-1}$ of $\mathrm{FW}$, with an average concentration of $715 \mathrm{mg} \mathrm{kg}{ }^{-1}$. 5caffeoylquinic acid was the most concentrated hydroxycinnamic acid and the most concentrated phenolic compound in fruits, with an average concentration close to $610 \mathrm{mg} \mathrm{kg}^{-1}$ FW and ranging from 79 to $1865 \mathrm{mg} \mathrm{kg}^{-1}$ (Figure 1). These results were consistent with previous studies done on cider apples and high compared to dessert apples (Table 2). In some varieties such as 'Ellis Bitter' or 'Harry Masters Jersey', (-)-epicatechin is the major fruit phenolic compound. ${ }^{4}$

Dihydrochalcones represent $4.8 \%$ of average total polyphenols in the fruit (Table 1). Phloridzin and phloretin xyloglucoside had proximate average concentrations in the progeny, close to $60 \mathrm{mg} \mathrm{kg}^{-1}$ of $\mathrm{FW}$ and ranging from 17 to $190 \mathrm{mg} \mathrm{kg}^{-1}$ for phloridzin (without one outlier at $250 \mathrm{mg} \mathrm{kg}^{-1}$ ), and from 6 to $180 \mathrm{mg} \mathrm{kg}^{-1}$ for phloretin xyloglucoside (Fig. 1). These results were consistent with previous studies on cider apples and higher than those on dessert apples (Table 2). 
Flavonols represent $3.5 \%$ of total phenolic compounds, ranging from 20 to $274 \mathrm{mg} \mathrm{kg}^{-1}$ of FW, with an average concentration of $94 \mathrm{mg} \mathrm{kg}^{-1}$ (Table 1). These concentrations were low compared to previous studies performed on English cider apples where flavonol concentrations ranged from 149 to $1215 \mathrm{mg} \mathrm{kg}^{-1}$ of FW in peel. ${ }^{4}$ However, the range between the most and the least concentrated individuals was higher in our progeny (14-fold) than in English varieties (8-fold). Quercitrin was the most concentrated flavonol, with $49 \%$ of total flavonol concentration ranging from 6 to $161 \mathrm{mg} \mathrm{kg}^{-1}$ of $\mathrm{FW}$ (Fig. 1). In previous works, hyperin was commonly more concentrated than quercitrin. ${ }^{4,34}$ On average, it represented $34 \%$ and $33 \%$, whereas quercitrin represented only $13 \%$ and $23 \%$ of the total flavonols in English cider and dessert apple varieties, respectively. However, in some varieties such as the ancestor, 'Florina', quercitrin was the most concentrated flavonol, with a concentration of 45 $\mathrm{mg} \mathrm{kg}{ }^{-1}$ of $\mathrm{FW}$, whereas the concentration of hyperin was $29 \mathrm{mg} \mathrm{kg}^{-1} \cdot{ }^{34}$ Rutin was the least concentrated flavonol (3.8\%) and the least concentrated phenolic compound, with concentrations ranging from 1 to $10 \mathrm{mg} \mathrm{kg}^{-1}$ of $\mathrm{FW}$ (without one outlier at $39 \mathrm{mg} \mathrm{kg}^{-1}$; Fig. 1). Anthocyanins quantified in fruits represented $0.2 \%$ of total phenolic compounds (Table 1 ). The maximum concentration of ideain obtained in the progeny was $58 \mathrm{mg} \mathrm{kg}^{-1}$ of $\mathrm{FW}$, which was low compared to previous studies on cider apples but higher than concentrations in dessert apples (Table 2).

ANOVA was carried out with 14 common individuals harvested in 2008 and 2009. The genetic effect, harvest year effect and the interaction genetic x year were significant for all compounds (Supplementary data, Table S1). For most compounds, the genetic factor is the most important. However, for the flavonols avicularin, hyperin, isoquercitrin and reynoutrin, the year effect was more important than the genetic effect. These results were obtained with only 14 individuals and they may not be very representative. Nevertheless, the instability and 
low repeatability of flavonols was previously reported in Malus x domestica germplasm grown in New Zealand. ${ }^{35}$ These variations were mainly explained by the sensitivity of flavonols to light and temperature.

PCA analyses were performed separately each year with all phenolic compounds because there were not enough common individuals between the two harvest years (Fig. 2). The first dimension was around $33 \%$ and $30 \%$, and the second around $19 \%$ and $16 \%$ in 2008 and 2009 respectively. Although these dimensions explain only $50 \%$ of all variables, these PCA can highlight existing correlations between variables best representing in the plane. For both years, a good correlation was observed within flavanols, on the one hand, and within flavonols on the other. No correlation between these two groups was observed. Previous studies on the 'Granny Smith' apple variety had already shown that phenolic compounds were highly correlated within their chemical groups. ${ }^{36}$ Similar observations were also reported in dessert apple progenies studied by Chagne et al. ${ }^{25}$ and Khan et al., ${ }^{26}$ with strong correlations between compounds of the same phenolic group. In contrast to our results, hyperin and reynoutrin were correlated with procyanidins in the skin. ${ }^{25}$ These results tend to show the regulation systems of the biosynthetic pathway of phenolic compounds which act more on an entire group of compound than one particular compound.

\section{Phenolic compounds in apple juices}

In cider industries, apples are rapped and pressed mechanically to get the juice. An enzymatic treatment can also be applied before pressing to hydrolyze the cell walls (Grimi et al., 2011). These devices are not suitable for the small amount of fruit that we had available, so we decided to prepare our juice samples with a centrifuge although we are conscious that this juice preparation procedure strongly differed from the current industrial processes. 
Nevertheless, decanter centrifuges are still used sometimes to produce industrial apple juices. Twelve major phenolic compounds of apple juices were measured by UHPLC-MS/MS for two harvest years: four flavanols $((+)$-catechin, $(-)$-epicatechin, procyanidins B1 and B2), four flavonols (avicularin, hyperin, quercitrin and rutin), three hydroxycinnamic acids (5caffeoylquinic acid, 4-caffeoylquinic acid and 4-p-coumaroylquinic acid) and the dihydrochalcones, phloridzin. In 2010, the dihydrochalcone, phloretin xyloglucoside, and ten other major procyanidins were also quantified. Since the addition of these 11 compounds makes comparisons with J09 difficult, only the results for J10 are presented below.

The total concentration of polyphenols in the juices was comprised between 740 and $3742 \mathrm{mg}$ $\mathrm{L}^{-1}$ of juice, with an average concentration of $1994 \mathrm{mg} \mathrm{L}^{-1}$ (Table 3). These results are in agreement with total polyphenol concentrations previously determined in juices prepared from cider apple varieties (Table 2). The Basque cider variety, 'Larrabetzu', was particularly concentrated, with a total phenolic content of $13600 \mathrm{mg} \mathrm{L}^{-1}$. The second most concentrated variety in this study was 'Mendexa 10', with a total polyphenol concentration of $4300 \mathrm{mg} \mathrm{L}$ ' ${ }^{13}$ However, total concentrations determined in dessert and German cider varieties were lower than ours (Table 2).

The largest group was the flavanols, with $50.7 \%$ of average total phenolic content in the juice (Table 3). The total concentration of flavanols ranged from 451 to $2168 \mathrm{mg} \mathrm{L}^{-1}$, with an average concentration of $1011 \mathrm{mg} \mathrm{L}^{-1}$. These results are consistent with a previous study where the total flavanol content of Basque cider apple juice determined with phloroglucinolysis analysis ranged from 347 to $3511 \mathrm{mg} \mathrm{L}^{-1}$, with an average concentration of 968.5 $\mathrm{mg} \mathrm{L}^{-1}{ }^{3}$. Procyanidin B2 was the most concentrated flavanol with an average concentration of $289 \mathrm{mg} \mathrm{L}^{-1}$, ranging from 120 to $650 \mathrm{mg} \mathrm{L}^{-1}$ (Fig. 3). The second one was ()-epicatechin, with concentrations ranging from 61 to $433 \mathrm{mg} \mathrm{L}^{-1}$, with an average 
concentration of $206.9 \mathrm{mg} \mathrm{L}^{-1}$. Procyanidin B2 represented an average of $28.6 \%$ and (-)epicatechin an average of $20.4 \%$ of the total flavanol content. Their concentrations were consistent with those determined for Basque cider varieties (Table 2). Depending on the variety, procyanidin B2 or (-)-epicatechin was the major flavanol compound. (-)-epicatechin represented between $6.5 \%$ and $29.7 \%$ and procyanidin B2 between $7.9 \%$ and $20.6 \%$ of the total flavanol content. $^{3}$ The least concentrated compound was $(+)$-catechin, with concentrations comprised between 13 and $143 \mathrm{mg} \mathrm{L}^{-1}$ of juice (without one outlier at $178 \mathrm{mg}$ $\mathrm{L}^{-1}$ ). (Fig. 3). These results were consistent with previous studies on Basque cider varieties (Table 2).

The second major phenolic group was hydroxycinnamic acids, with $43.3 \%$ of total phenolic compounds (Table 3). The total content ranged from 137 to $1788 \mathrm{mg} \mathrm{L}^{-1}$, with an average concentration of $863 \mathrm{mg} \mathrm{L}^{-1}$. 5-caffeoylquinic acid is the most concentrated hydroxycinnamic acid and the most concentrated phenolic compound in juices, ranging from 77 to $1413 \mathrm{mg} \mathrm{L}^{-1}$, with an average concentration of $700 \mathrm{mg} \mathrm{L}^{-1}$ (Fig. 3). The range of this compound in our progeny is particularly high (18-fold) compared to previous works on Spanish (4-fold), German (6-fold) and Basque (6-fold) cider apple varieties (Table 2).

Dihydrochalcones represented $3.6 \%$ of the total phenolic content in juices (Table 3). Total dihydrochalcones determined in our study ranged from 31 to $244 \mathrm{mg} \mathrm{L}^{-1}$, with an average concentration of $73 \mathrm{mg} \mathrm{L}^{-1}$. These results were consistent with previous studies on German cider varieties (Table 2). Phloretin xyloglucoside is more concentrated than phloridzin in our progeny, as previously reported in most cultivars (Fig. 3). 37, 38

Flavonols were the least concentrated compounds in our progeny, with $2.4 \%$ of the total content of phenolic compounds present in juices (Table 3). The concentration of this group ranged from 16 to $179 \mathrm{mg} \mathrm{L}^{-1}$, with an average concentration of $47 \mathrm{mg} \mathrm{L}^{-1}$. These results were very high compared to those previously obtained (Table 2). Quercitrin is the most 
concentrated flavonol, with $55 \%$ of total flavonol concentration, ranging from 5 to $98 \mathrm{mg} \mathrm{L}^{-1}$ (without one outlier at $130 \mathrm{mg} \mathrm{L}^{-1}$ ). Rutin is the least concentrated flavonol (1.4\%) and the least concentrated phenolic compound, with concentrations ranging from 0.06 to $3.35 \mathrm{mg} \mathrm{L}^{-1}$ of juice. These high concentrations compared to previous studies could be due to the extraction method used for juice preparation since we used a juice extractor, whereas pressing was used in previous studies. ${ }^{3,38}$

The same profiles were obtained for common compounds quantified in both J09 and J10. However, average concentrations obtained in J09 for catechins (207 mg L $\left.\mathrm{L}^{-1}\right)$, hydroxycinnamic acids $\left(755 \mathrm{mg} \mathrm{L}^{-1}\right)$ and flavonols $\left(31 \mathrm{mg} \mathrm{L}^{-1}\right)$ were lower than those obtained in J10. A wider range was obtained for these groups (catechins: from 22 to $584 \mathrm{mg}$ $\mathrm{L}^{-1}$; hydroxycinnamic acids: from 82 to $2053 \mathrm{mg} \mathrm{L}^{-1}$; flavonols: from 8 to $118 \mathrm{mg} \mathrm{L}^{-1}$ ), which could be explained by the larger number of individuals studied (209 individuals in J09 and 123 in J10).

ANOVA was performed with 57 common progenies harvested in 2009 and 2010 for the 12 compounds quantified in both years. The genetic effect, harvest year effect and the interaction genetic x year were significant for all compounds except for $(+)$-catechin and avicularin, which did not have significant effects for harvest year and the genetic $\mathrm{x}$ year interaction, respectively (Supplementary data, TableS2). The genetic effect was always the biggest one, except for hyperin that had a dominant year effect.

PCA analyses were performed separately for both years using all of the phenolic compounds. The first dimension was around $37 \%$ and $29 \%$, and the second around $15 \%$ and $16 \%$ in 2009 
and 20109 respectively. The results obtained were close to those obtained in fruits. A good correlation was observed for flavanols, on the one hand, and for flavonols on the other, and no correlation between these two groups was observed. The two acids, 4-caffeoylquinic acid and 4-p-coumaroylquinic acid, were also correlated in 2010 (Fig. 4).

\section{Extractability of polyphenols from the fruit to the juice}

Globally, similar profiles were obtained in fruits and juices with flavanols as the major group, followed by hydroxycinnamic acids, dihydrochalcones and flavonols. However, in fruits, flavanols and hydroxycinnamic acids represented 65 and $26.4 \%$ of the average total phenolic content, respectively, whereas in juices, they represented 50.7 and $43.3 \%$, respectively. These differences were directly linked to the extraction yield of compounds during fruit processing. The degradation of compounds by oxidation was minimized by the addition of sodium fluoride. The detailed polyphenol profiles of the fruits were thus compared to the corresponding juices (same year of harvest) according to the method used by Guyot et al. ${ }^{6}$ The mean extraction yield was then calculated and is illustrated in Fig. 5. Hydroxycinnamic acid was the least affected group following the juice preparation, with an average extraction yield of $67 \%$. Flavanol monomers were the second group that had the best extraction yield, around $48 \%$. Since the total procyanidin content was not evaluated in juices in 2009 , it was not possible to determine the extraction yield of this group. However, the average concentration of procyanidins determined in juices prepared in 2010 compared to the total procyanidin content obtained in fruits showed an average extraction yield of around $30 \%$.

These results are consistent with those obtained by Guyot et al. ${ }^{6}$ The high association between procyanidins and the solid parts of the fruit, particularly cell wall materials, explains this low extraction yield. ${ }^{16}$ However, individually, procyanidin B2 had a significantly higher extraction yield compared to monomers (CAT and ECAT on Fig. 5). This result could be in part 
explained by the better solubility in water of procyanidin B2 compared to (-)-epicatechin, which had an octanol-water partition coefficient of 0.172 and 1.299 , respectively. ${ }^{39}$ Moreover, the tanning effect of procyanidins is directly related to the degree of polymerization. ${ }^{40}$ Since procyanidin B2 is a dimer, its association with the proteins of the matrix was less than other more polymerized tannins. The extraction yield was particularly low for flavonols, around $18 \%$ (Fig. 5). In fruits, more flavonol compounds could be quantified compared to the juices. Isoquercitrin was not detected and reynoutrin was not sufficiently concentrated to be quantified in juices with our method. This low extraction yield could be explained by the localization of these compounds in the fruit skin. Nevertheless, in our progeny, the extraction yield determined for flavonols was better than that previously reported in cider apple varieties, ranging around $10 \%{ }^{41}$ The difference could be due to the juice extraction method used since they used a commercial scale pressing method, whereas our fruits were cored and crushed with a juice extractor. In 2009, since the dihydrochalcones, phloretin xyloglucoside, was not quantified, the average extraction yield was only estimated for phloridzin, around $17 \%$ (Fig. 5). If we consider the average concentration of total dihydrochalcones determined in $\mathrm{J} 10$ compared to that determined in fruits, the extraction yield was better, nearly $33 \%$. Nevertheless, these results are very low compared to previous results that showed an extraction yield of $80 \%{ }^{6}$ However, to determine the fruit content, Guyot et al. ${ }^{6}$ had only considered the flesh of apples, whereas the skin and the seeds, very concentrated in dihydrochalcones, were included in our study. ${ }^{3,42,43}$ The extraction yield previously measured by Guyot et al. ${ }^{6}$ had therefore probably been overestimated. Finally, ideain was exclusively found in fruits, which is the confirmation of its localization in the fruit skin. 


\section{Variability of polyphenol contents between two apple progenies}

The variability observed in the progeny was representative of that observed for different cider apple varieties. In our progeny, 4-p-coumaroylquinic acid had the largest range in fruits (125fold), and hyperin had the lowest (13-fold). The variability of DPn was estimated in a progeny for the first time. It was almost 3-fold depending on the individuals. In juices, rutin had the largest range since it was 56 times more concentrated in the most concentrated individual compared to the least concentrated. Procyanidin B2 had the lowest one, less than 6-fold. The variability observed in juices was less than that observed in fruits. This could be explained by the loss of some phenolic compounds during the juice preparation. However, rutin was the only compound for which the variability was greater in the juices than in the fruits.

The comparison with the New Zealand study on dessert apple progeny showed that the variability observed in our progeny was similar for 4-p-coumaroylquinic acid and reynoutrin, but was higher for isoquercitrin and quercitrin in our progeny. However, the variability observed in our progeny was low for flavanols, DHC and anthocyanins. Indeed, the difference between the most and the least concentrated individual in the dessert progeny was 172-fold for $(+)$-catechin and 203-fold for ideain in the skin, and 61-fold for phloridzin or phloretin xyloglucoside in the flesh. ${ }^{25}$ In our cider progeny, they were 35-, 18-, 30- and 15-fold, respectively (Table 1). These comparisons were based on minimum and maximum values found in progenies. These results have to be examined with great care since extreme values were not critically representative of the entire progeny. In addition, the Chagne et al. ${ }^{25}$ study was performed for skin and flesh separately, which could have accentuated the variability observed compared to the whole fruit. 


\section{CONCLUSION}

The genetic basis of the progeny under study resulting from a cross between a dessert apple and a hybrid of a cider apple, allowed us to obtain mean values and ranges for each compound that were very similar to previous studies on phenotypic variability in cider apples for both fruit extracts and juices. As expected, fruits were more concentrated than juices for all the compounds detected. The differences observed between fruits and juices for each polyphenol compound can easily be explained by their various extractability properties: hydroxycinnamic acids were the most extractable group, followed by flavanol monomers, procyanidins, dihydrochalcones, flavonols and anthocyanins. However, phenolic profiles were similar between fruits and juices with 5-caffeoylquinic acid and rutin as the most and least concentrated compounds, respectively. ANOVA results have shown a high genetic effect for all compounds, which suggests a considerable part of genetic variability in the expression of these traits. However, for flavanols, a greater effect of the harvest year was observed in both fruits and juices, consistent with their high sensitivity to light and temperature. The high genetic effects will allow us to use this dataset for future QTL mapping analysis.

\section{ACKNOWLEDGEMENTS}

The authors would like to thank M. Boucourt and E. Lepautremat for their technical assistance in sample harvesting and preparation, R. Mabon, A. Leroux and C. Baron for their technical contribution to sample preparation and polyphenol analysis, J.M. Le Quéré for his help collecting and organizing the data, and the team of the Horticulture Experimental Unit of INRA, Angers-Nantes, that took care of the trees. This study was financially supported by funding for a $\mathrm{PhD}$ grant from the SFR 149 QUASAV, Angers, France, and the INNOVACIDRE project funded by the Region Bretagne, Pays de la Loire and Basse 
Normandie. Thus, we also thank the Pôle Agronomique Ouest (PAO) for their significant contribution to the design and the management of this project.

\section{REFERENCES}

1. Bore J-M and Fleckinger J, Pommiers à cidre_variétés de France. Paris (1997).

2. Sanoner P, Guyot S, Marnet N, Molle D and Drilleau J-F, Polyphenol Profiles of French Cider Apple Varieties (Malus domestica sp.). J Agric Food Chem 47:4847-4853 (1999).

3. Alonso-Salces RM, Barranco A, Abad B, Berrueta LA, Gallo B and Vicente F, Polyphenolic Profiles of Basque Cider Apple Cultivars and Their Technological Properties. J Agric Food Chem 52:2938-2952 (2004).

4. Marks SC, Mullen W and Crozier A, Flavonoid and chlorogenic acid profiles of English cider apples. J Sci Food Agric 87:719-728 (2007).

5. Guyot S, Le Bourvellec C, Marnet $\mathrm{N}$ and Drilleau JF, Procyanidins are the most Abundant Polyphenols in Dessert Apples at Maturity. LWT 35:289-291 (2002).

6. Guyot S, Marnet N, Sanoner P and Drilleau J-F, Variability of the Polyphenolic Composition of Cider Apple (Malus domestica) Fruits and Juices. J Agric Food Chem 51:6240-6247 (2003).

7. Lea AGH and Arnold GM, The phenolics of ciders: Bitterness and astringency. $J$ Sci Food Agric 29:478-483 (1978).

8. Oszmianski J and Lee CY, Enzymic oxidative reaction of catechin and chlorogenic acid in a model system. J Agric Food Chem 38:1202-1204 (1990).

9. Song Y, Yao Y-X, Zhai H, Du Y-P, Chen F and Wei S-W, Polyphenolic Compound and the Degree of Browning in Processing Apple Varieties. Agric Sci China 6:607-612 (2007). 
10. Guyot S, Bernillon S, Poupard P and Renard CMGC, Multiplicity of phenolic oxydation products in apple juices and ciders, from synthetic medium to commercial products, in Recent advances in polyphenol research, pp 278-292 (2008).

11. Herrero M, Cuesta I, Garcia LA and Diaz M, Changes in Organic Acids During Malolactic Fermentation at Different Temperatures in Yeast-Fermented Apple Juice. $J$ Inst Brew 105:191-195 (1999).

12. Crozier A, Jaganath IB and Clifford MN, Dietary phenolics: chemistry, bioavailability and effects on health. $R$ Soc Chem 26:1001-1043 (2009).

13. Biedrzycka E and Amarowicz R, Diet and Health: Apple Polyphenols as Antioxydants. Food Rev Int 24:235-251 (2008).

14. Boyer J and Liu RH, Apple phytochemicals and their health benefits. Nutr J 3:5 (2004).

15. Tsao R, Yang R, Young J and Zhu H, Polyphenolic Profiles in Eight Apple Cultivars Using High-Performance Liquid Chromatography (HPLC). J Agric Food Chem 51:6347-6353 (2003).

16. Renard CMGC, Baron A, Guyot S and Drilleau JF, Interactions between apple cell walls and native apple polyphenols: quantification and some consequences. Biol Macromol 29:115-125 (2001).

17. Ding $\mathrm{C}-\mathrm{K}$, Chachin $\mathrm{K}$, Ueda $\mathrm{Y}$ and Imahori $\mathrm{Y}$, Purification and Properties of Polyphenol Oxidase from Loquat Fruit. J Agric Food Chem 46:4144-4149 (1998).

18. Huang YF, Doligez A, Fournier-Level A, Le Cunff L, Bertrand Y, Canaguier A, Morel C, Miralles V, Veran F, Souquet J-M, Cheynier V, Terrier N and This P, Dissecting genetic architecture of grape proanthocyanidin composition through quantitative trait locus mapping. BMC Plant Biol 12:30 (2012). 
19. Shao Y, Jin L, Zhang G, Lu Y, Shen Y and Bao J, Association mapping of grain color, phenolic content, flavonoid content and antioxidant capacity in dehulled rice. Theor Appl Genet 122:1005-1016 (2011).

20. Rezaeizad A, Wittkop B, Snowdon R, Hasan M, Mohammadi V, Zali A and Friedt W, Identification of QTLs for phenolic compounds in oilseed rape (Brassica napus L.) by association mapping using SSR markers. Euphytica 177:335-342 (2011).

21. Barriere $\mathrm{Y}$, Thomas $\mathrm{J}$ and Denoue D, QTL mapping for lignin content, lignin monomeric composition, p-hydroxycinnamate content, and cell wall digestibility in the maize recombinant inbred line progeny F838 x F286. Plant Sci 175:585-595 (2008).

22. Fournier-Level A, Le Cunff L, Gomez C, Doligez A, Ageorges A, Roux C, Bertrand Y, Souquet J-M, Cheynier V and This P, Quantitative Genetic Bases of Anthocyanin Variation in Grape (Vitis vinifera L. ssp. sativa) Berry: A Quantitative Trait Locus to Quantitative Trait Nucleotide Integrated Study. Genet 183:1127-1139 (2009).

23. Dobson P, Graham J, Stewart D, Brennan R, Hackett CA and McDougall GJ, Overseasons Analysis of Quantitative Trait Loci Affecting Phenolic Content and Antioxidant Capacity in Raspberry. J Agric Food Chem 60:5360-5366 (2012).

24. Hackett CA, Russell J, Jorgensen L, Gordon SL and Brennan RM, Multi-environment QTL mapping in blackcurrant (Ribes nigrum L.) using mixed models. Theor Appl Genet 121:1483-1488 (2010).

25. Chagne D, Krieger C, Rassam M, Sullivan M, Fraser J, Andre C, Pindo M, Troggio M, Gardiner SE, Henry RA, Allan AC, McGhie TK and Laing WA, QTL and candidate gene mapping for polyphenolic composition in apple fruit. BMC Plant Biol 12:12 (2012)

26. Khan SA, Chibon P-Y, de Vos RCH, Schipper BA, Walraven E, Beekwilder J, van Dijk T, Finkers R, Visser RGF, van de Weg EW, Bovy A, Cestaro A, Velasco R, Jacobsen E 
and Schouten HJ, Genetic analysis of metabolites in apple fruits indicates an mQTL hotspot for phenolic compounds on linkage group 16. J Exp Bot 63:2895-2908 (2012).

27. Schieber A, Keller P and Carle R, Determination of phenolic acids and flavonoids of apple and pear by high-performance liquid chromatography. J Chrom A 910:265-273 $(2001)$

28. Renard CMGC, Variability in cell wall preparations : quantification and comparison of common methods. Carbohydr Polym 60:515-522 (2005).

29. Guyot S, Marnet N, Sanoner P and Drilleau J-F, Direct thiolysis on crude apple materials for high-performance liquid chromatography characterization and quantification of polyphenols in cider apple tissues and juices. Methodes Enzym 335:5770 (2001).

30. Kennedy JA and Jones GP, Analysis of Proanthocyanidin Cleavage Products Following Acid-Catalysis in the Presence of Excess Phloroglucinol. J Agric Food Chem 49:1740$1746(2001)$.

31. Matthews S, Mila I, Scalbert A, Pollet B, Lapierre C, Herve du Penhoat CLM, Rolando C and Donnelly DMX, Method for estimation of proanthocyanidins based on their acid depolymerization in the presence of nucleophiles. J Agric Food Chem 45:1195-1201 (1997).

32. Marnet N, Guyot S, Drilleau JF and Renard CMGC, Phloroglucinolysis applied to the characterisation and the quantification of procyanidins in apples and their derived products, in Polyphenols Communications 2002 XXI International Conference on Polyphenols, Ed by Hadrani IE, Marrakech - Maroc, pp 457-458 (2002).

33. R Development Core Team, R: A language and environment for statistical computing., Ed by R Fundation for Statistical Computing, Vienna, Austria (2008). 
34. Wojdylo A, Oszmianski J and Laskowski P, Polyphenolic Compounds and Antioxidant Activity of New and Old Apple Varieties. J Agric Food Chem 56:6520-6530 (2008).

35. Volz RK and McGhie TK, Genetic variability in apple fruit polyphenol composition in Malus x domestica and Malus sieversii germplasm grown in New Zealand. J Agric Food Chem 59:11509-11521 (2011).

36. Perez-Ilzarbe J, Hernandez T, Estrella I and Vendrell M, Cold storage of apples (cv. Granny Smith) and changes in phenolic compounds. Z Lebensm Unters Forsch A 204:52-55 (1997).

37. Mangas JJ, Rodriguez R, Suarez B, Picinelli A and Dapena E, Study of the Phenolic Profile of Cider Apple Cultivars at Maturity by Multivariate Techniques. J Agric Food Chem 47:4046-4052 (1999).

38. Kahle K, Krauss M and Richling E, Polyphenol profiles of apple juices. Mol Nutr Food Res 49:797-806 (2005).

39. Zanchi D, Konarev PV, Tribet C, Baron A, Svergun DI and Guyot S, Rigidity, conformation, and solvatation of native and oxidized tannin macromolecules in waterethanol solution. J Chem Phys 130:245103 (2009).

40. De Freitas V and Mateus N, Nephelometric study of salivary protein-tannin aggregates. J Sci Food Agric 82:113-119 (2002).

41. Price KR, Prosser T, Richetin AMF and Rhodes MJC, A comparison of the flavonol content and composition in dessert, cooking and cider-making apples; distribution within the fruit and effect of juicing. Food Chem 66:489-494 (1999).

42. Khanizadeh S, Tsao R, Rekika D, Yang R, Charles M-T and Rupasinghe V, Polyphenol composition and total antioxidant capacity of selected apple genotypes for processing. $J$ Food Comp Anal 21:396-401 (2008). 
43. Guyot S, Marnet N, Laraba D, Sanoner P and Drilleau J-F, Reversed-Phase HPLC following Thiolysis for Quantitative Estimation and Characterization of the Four Main Classes of Phenolic Compounds in Different Tissue Zones of a French Cider Apple Variety (Malus domestica Var. Kermerrien). J Agric Food Chem 46:1698-1705 (1998). 
Table 1. Mean concentration ( $\mathrm{mg} \mathrm{kg}^{-1}$ of fresh weight) of phenolic compounds present in the whole fruit (2008 and 2009 harvest year) ${ }^{\mathrm{a}}$

\begin{tabular}{llllllllll}
\hline & $\begin{array}{l}\text { Total } \\
\text { catechins }\end{array}$ & $\begin{array}{l}\text { Total } \\
\text { PCA }\end{array}$ & $\begin{array}{l}\text { Total } \\
\text { flavanols }\end{array}$ & DPn & $\begin{array}{l}\text { Total } \\
\text { HA }\end{array}$ & $\begin{array}{l}\text { Total } \\
\text { DHC }\end{array}$ & $\begin{array}{l}\text { Total } \\
\text { flavonols }\end{array}$ & Ideain & $\begin{array}{l}\text { Total } \\
\text { polyphenols }\end{array}$ \\
\hline Average & 253 & 1508 & 1761 & 30 & 715 & 131 & 94 & 13 & 2707 \\
Median & 237 & 1394 & 1644 & 29 & 654 & 127 & 88 & 11 & 2488 \\
Minimum & 33 & 376 & 592 & 21 & 86 & 35 & 20 & 3 & 1058 \\
Maximum & 656 & 4112 & 4769 & 56 & 2000 & 332 & 274 & 58 & 6418 \\
\hline
\end{tabular}

a: PCA: procyanidins; DPn: average degree of polymerization of flavanols; HA: hydroxycinnamic acids; DHC: dihydrochalcones.

": The average, median, minimum and maximum concentrations of ideain were determined for the 82 individuals for which ideain were detected. 134 individuals had no anthocyanins.

This article is protected by copyright. All rights reserved. 
Table 2. Range of total polyphenol content, total procyanidins determined with acidolysis reaction, polymerization degree of flavanols and some other phenolic compounds in fruit (expressed in $\mathrm{mg} \mathrm{kg}^{-1}$ of fresh weight) and juice (expressed in $\mathrm{mg} \mathrm{L}^{-1}$ ) of different apple varieties ${ }^{\mathrm{a}}$

\begin{tabular}{|c|c|c|c|c|c|c|c|c|c|}
\hline \multicolumn{2}{|c|}{ Number and type of apple varieties } & \multirow{2}{*}{\begin{tabular}{|c|} 
Total polyphenols \\
$546-6306$
\end{tabular}} & \multirow[t]{2}{*}{ Total PCA } & \multirow{2}{*}{$\begin{array}{c}\text { ECAT } \\
116-2095\end{array}$} & \multirow{2}{*}{$\begin{array}{c}\text { CAT } \\
10-265\end{array}$} & \multirow{2}{*}{$\begin{array}{c}\text { B2 } \\
107-1362\end{array}$} & \multirow[t]{2}{*}{ DP flavanols } & \multirow{2}{*}{$\begin{array}{c}\text { 5CQA } \\
30-1163\end{array}$} & \multirow{2}{*}{$\begin{array}{c}\text { References } \\
4\end{array}$} \\
\hline 19 English cider & peel $\left(\mathrm{mg} \mathrm{kg}^{-1}\right.$ of $\left.\mathrm{FW}\right)$ & & & & & & & & \\
\hline apples & flesh ( $\mathrm{mg} \mathrm{kg}^{-1}$ of $\left.\mathrm{FW}\right)$ & $485-4920$ & & ND-2225 & $6-408$ & ND-1368 & & 69-1766 & \\
\hline $\begin{array}{l}2 \text { juices, } 12 \text { French } \\
\text { and } 1 \text { English cider } \\
\text { apples }\end{array}$ & $\left(\mathrm{mg} \mathrm{kg}^{-1}\right.$ of FW) & $1040-6990$ & $515-4731$ & $\operatorname{tr}-1410$ & $\operatorname{tr}-154$ & & $42-503$ & $154-1195$ & 2 \\
\hline 67 dessert apples & $\left(\mathrm{mg} \mathrm{kg}^{-1}\right.$ of $\left.\mathrm{FW}\right)$ & $1046-5448$ & $469-4679$ & $13-551$ & $2-145$ & $137-400$ & $6-57$ & 3-592 & $34 \mathrm{~b}$ \\
\hline $\begin{array}{l}31 \text { Basque cider } \\
\text { apples }\end{array}$ & $\left(\mathrm{mg} \mathrm{L}^{-1}\right)$ & $660-13600$ & $347-3511$ & $39-822$ & $3.3-40.7$ & $47-550$ & $2.7-4.6$ & $172-1099$ & 3 \\
\hline $\begin{array}{l}7 \text { German cider } \\
\text { apples }\end{array}$ & $\left(\mathrm{mg} \mathrm{L}^{-1}\right)$ & $261.2-970$ & & $29.8-189.1$ & $3-60$ & 29.2-138.4 & & $80.6-487.6$ & 38 \\
\hline 46 Spanish cider & 1994 season $\left(\mathrm{mg} \mathrm{L}^{-1}\right)$ & $570-2060$ & & $4.1-234.6$ & & ND-222.9 & & 25.1-377.1 & 37 \\
\hline apples & 1995 season $\left(\mathrm{mg} \mathrm{L}^{-1}\right)$ & $750-2420$ & & ND-206.5 & & ND-246.9 & & $21.2-350.5$ & \\
\hline 4 dessert apples & $\left(\mathrm{mg} \mathrm{L}^{-1}\right)$ & $154.4-178$ & & $15.1-51.4$ & $2.5-7$ & $29.6-42.5$ & & $32.7-54.1$ & 38 \\
\hline
\end{tabular}

\begin{tabular}{|c|c|c|c|c|c|c|c|c|c|c|}
\hline \multicolumn{2}{|c|}{ Number and type of apple varieties } & DHC & PLZ & XPL & Total flavonols & HY & QR & $\mathbf{R U}$ & ID & References \\
\hline 19 English cider & peel $\left(\mathrm{mg} \mathrm{kg}^{-1}\right.$ of FW) & & $25-1061$ & ND-201 & & $40-520$ & $18-236$ & $2-6$ & ND-494 & 4 \\
\hline apples & flesh ( $\mathrm{mg} \mathrm{kg}^{-1}$ of FW) & & $16-159$ & ND-73 & & ND-1.2 & ND-12 & & ND-12 & \\
\hline $\begin{array}{l}2 \text { juices, } 12 \text { French } \\
\text { and } 1 \text { English cider } \\
\text { apples }\end{array}$ & $\left(\mathrm{mg} \mathrm{kg}^{-1}\right.$ of $\left.\mathrm{FW}\right)$ & & $16-102$ & $10-98$ & & & & & & 2 \\
\hline 67 dessert apples & $\left(\mathrm{mg} \mathrm{kg}^{-1}\right.$ of FW) & & $1-61$ & $3-41$ & & $2-107$ & $4-138$ & ND-19 & ND-20 & $34 \mathrm{~b}$ \\
\hline $\begin{array}{l}31 \text { Basque cider } \\
\text { apples }\end{array}$ & $\left(\mathrm{mg} \mathrm{L}^{-1}\right)$ & & $11-92$ & $15-137$ & & $0.34-4$ & $0.48-6.5$ & & & 3 \\
\hline $\begin{array}{l}7 \text { German cider } \\
\text { apples }\end{array}$ & $\left(\mathrm{mg} \mathrm{L}^{-1}\right)$ & $33.5-171$ & $13.2-93.6$ & 20.3-135.9 & $\operatorname{tr}-26.7$ & $\operatorname{tr}-8.1$ & $\operatorname{tr}-4.6$ & ND-0.8 & & 38 \\
\hline $\begin{array}{l}46 \text { Spanish cider } \\
\text { apples }\end{array}$ & $\begin{array}{l}1994 \text { season }\left(\mathrm{mg} \mathrm{L}^{-1}\right) \\
1995 \text { season }\left(\mathrm{mg} \mathrm{L}^{-1}\right)\end{array}$ & & $\begin{array}{l}3.7-36.6 \\
2.5-32.4\end{array}$ & $\begin{array}{c}4-159.1 \\
3.3-107.2\end{array}$ & & & & & & 37 \\
\hline 4 dessert apples & $\left(\mathrm{mg} \mathrm{L}^{-1}\right)$ & $9.8-35.2$ & $4.1-9.3$ & $2.7-25.9$ & $\operatorname{tr}-3.6$ & $\operatorname{tr}-2.2$ & $\operatorname{tr}-1.9$ & & & 38 \\
\hline
\end{tabular}

a: PCA: procyanidins; ECAT: (-)-epicatechin; CAT: (+)-catechin; B2: procyanidin B2; DP: polymerization degree; 5CQA: 5-caffeoylquinic acid; DHC: dihydrochalcones; PLZ: phloridzin; XPL: phloretin xyloglucoside; HY: hyperin; QR: quercitrin; RU: rutin; ID: ideain; ND: not detected; tr: trace.

${ }^{b}$ : Values presented by Wojdylo et al. (2008) were modified to be expressed in g of FW. We chose an arbitrary correction factor of 5.

This article is protected by copyright. All rights reserved. 
Table 3. Concentration $\left(\mathrm{mg} \mathrm{L}^{-1}\right)$ of phenolic compounds present in the juice (2010 harvest year $)^{\mathrm{a}}$

\begin{tabular}{lccccccc}
\hline & $\begin{array}{c}\text { Total } \\
\text { catechins }\end{array}$ & $\begin{array}{c}\text { Total } \\
\text { PCA }\end{array}$ & $\begin{array}{c}\text { Total } \\
\text { flavanols }\end{array}$ & $\begin{array}{c}\text { Total } \\
\text { HCA }\end{array}$ & $\begin{array}{c}\text { Total } \\
\text { flavonols }\end{array}$ & $\begin{array}{c}\text { Total } \\
\text { DHC }\end{array}$ & $\begin{array}{c}\text { Total } \\
\text { polyphenols }\end{array}$ \\
\hline Average & 249 & 762 & 1011 & 863 & 47 & 73 & 1994 \\
Median & 231 & 716 & 988 & 883 & 43 & 65 & 1911 \\
Minimum & 61 & 339 & 451 & 137 & 16 & 31 & 740 \\
Maximum & 611 & 1604 & 2168 & 1788 & 177 & 244 & 3742 \\
\hline
\end{tabular}

${ }^{\mathrm{a}}$ : Abbreviations: see Table 1 

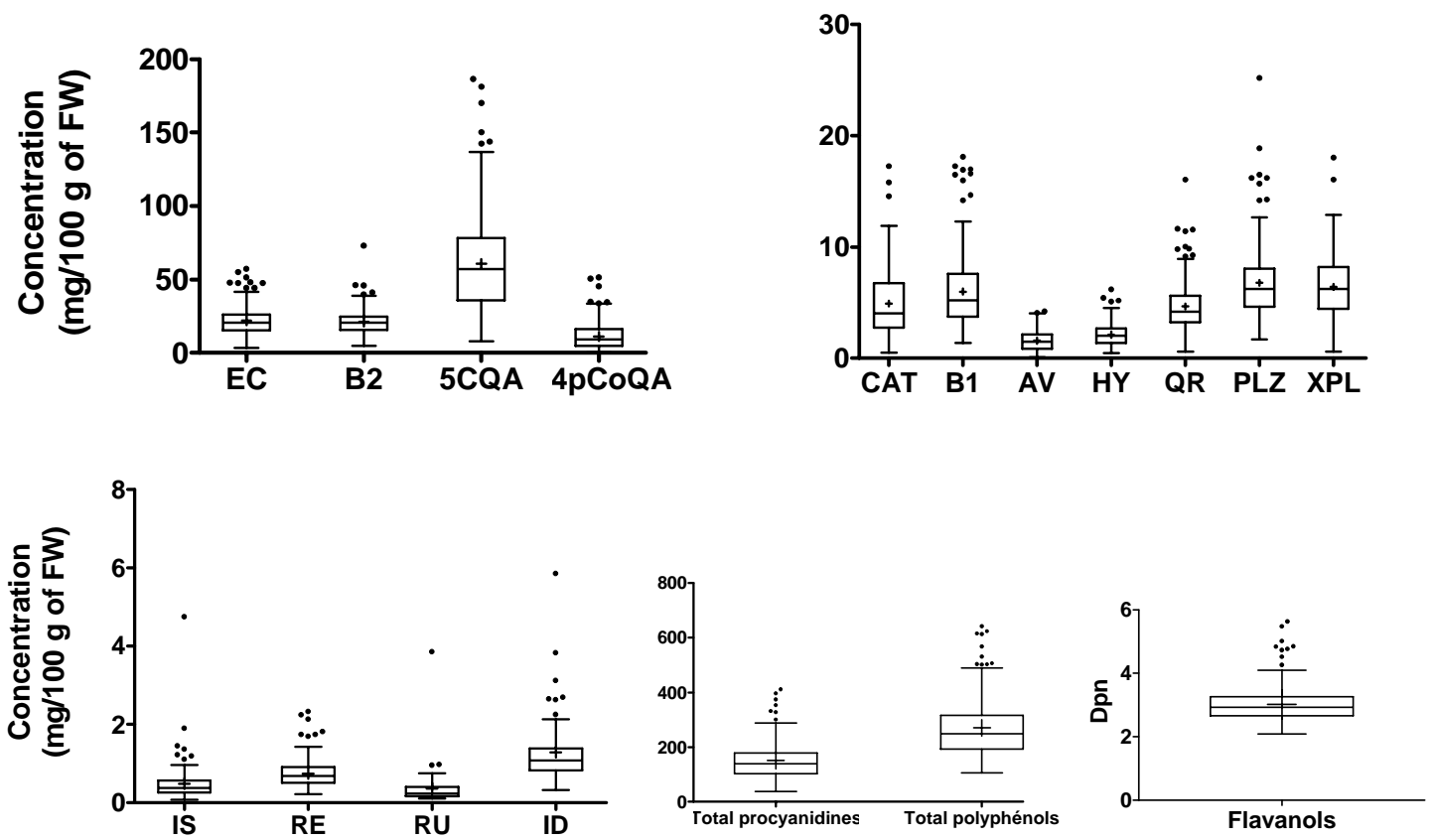

Figure 1. Turkey boxplot for the mean polyphenol concentration $(\mathrm{mg} / 100 \mathrm{~g}$ of fresh weight) in the whole fruit (2008 and 2009 harvest years). EC: (-)-epicatechin; CAT: (+)-catechin; B1: procyanidin $\mathrm{B} 1$; $\mathrm{B} 2$ : procyanidin $\mathrm{B} 2$; 5CQA: 5-caffeoylquinic acid; 4pCoQA: 4-pcoumaroylquinic acid; AV: avicularin; HY: hyperin; IS: isoquercitrin; QR: quercitrin; RE: reynoutrin; RU: rutin; PLZ: phloridzin; XPL: phloretin xyloglucoside; ID: ideain; DPn: mean polymerization degree. Outliers and means are represented with circles and crosses, respectively.

Source file: GraphPadPrism 5.01 

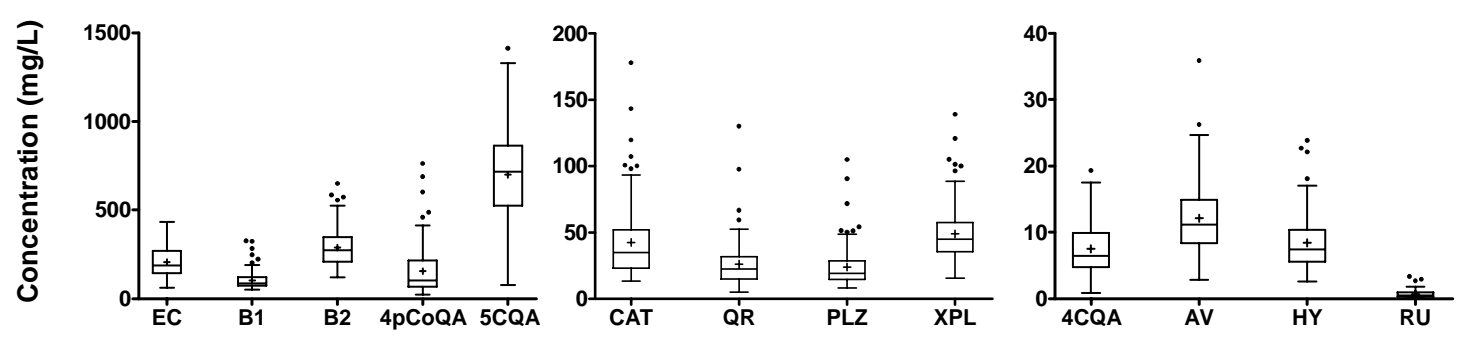

Figure 3. Turkey boxplot for the mean polyphenol concentration $(\mathrm{mg} / \mathrm{L})$ in juices prepared in 2010. Abbreviations: see Fig. 1; 4pCoQA: 4-p-coumaroylquinic acid. Outliers and means are represented with circles and crosses, respectively.

Source file: GraphPadPrism 5.01 

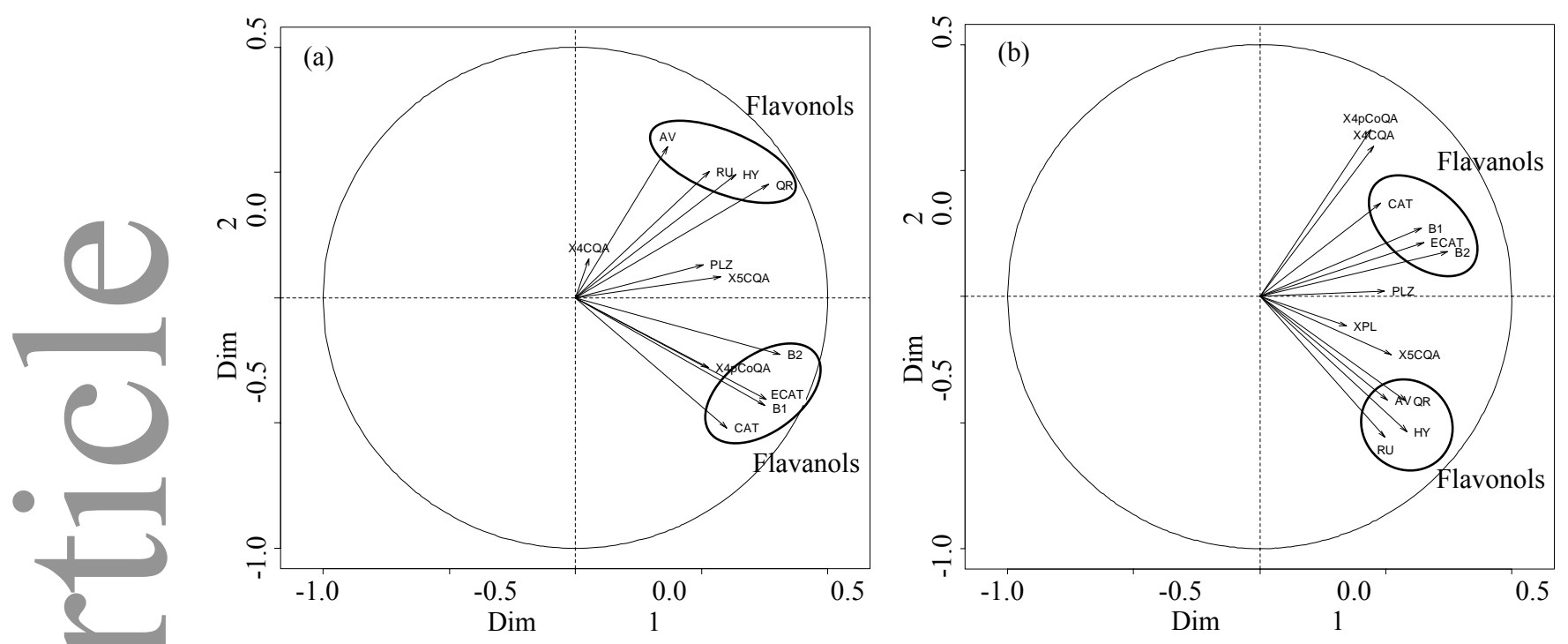

Figure 4. PCA of phenolic compounds quantified in juices prepared in 2009 (a) and 2010 (b). Abbreviations: see Fig. 1; X4CQA: 4-caffeoylquinic acid; X4pCoQA: 4-p-coumaroylquinic acid; X5CQA: 5-caffeoylquinic acid.

Source file: R 2.13.1

This article is protected by copyright. All rights reserved. 


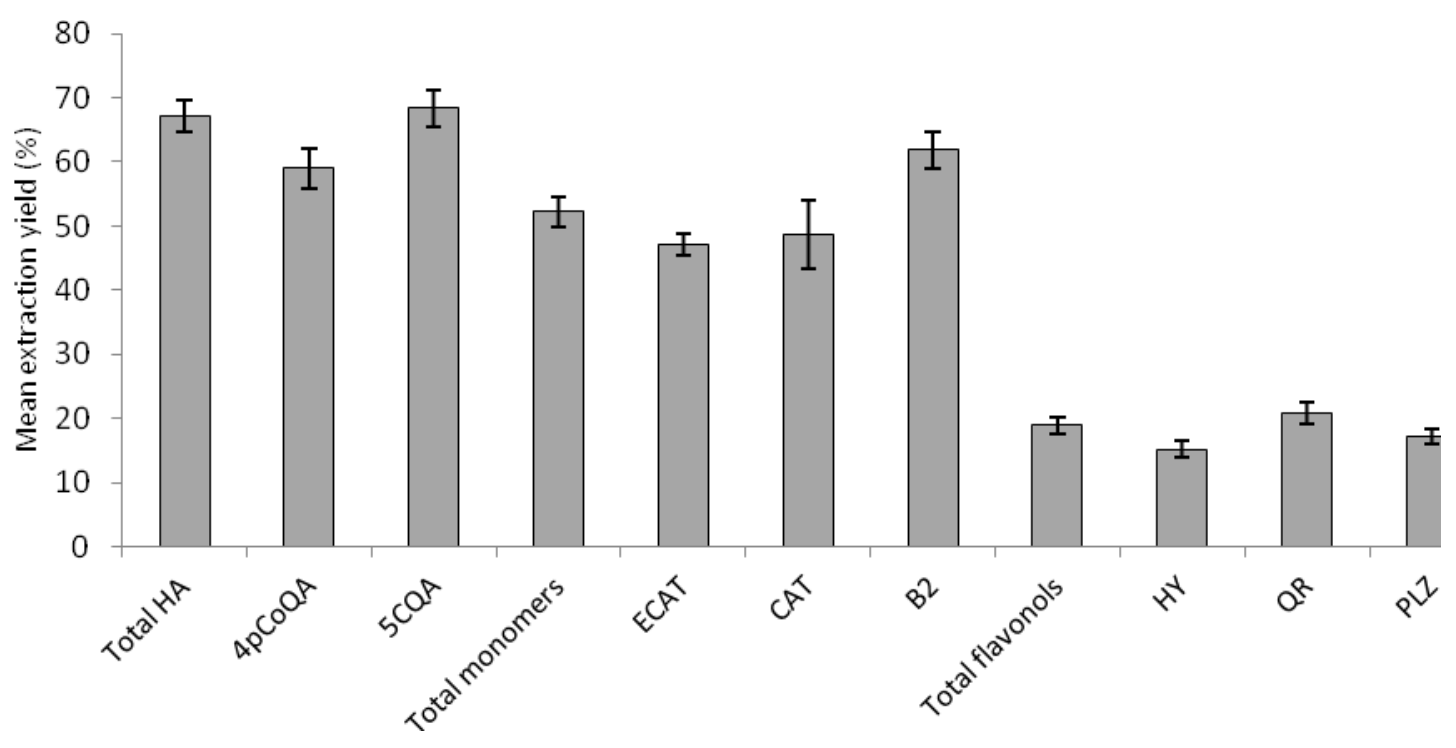

Figure 5. Mean extractability level (in \%) of individual phenolic compounds as well as total hydroxycinnamic acids (HA), flavanol monomers, and flavonols determined within the 124 common individuals analyzed both for fruits and juices in 2009. Abbreviations: see Fig. 1.

Source file: excel 2007 